\title{
Identificación de antígenos de aislamientos colombianos de Giardia duodenalis reconocidos por IgG total y subclases
}

\author{
Jenny Fabiola Hernández ${ }^{1}$, Sofía Duque ${ }^{1,2}$, Adriana Arévalo ${ }^{1}$, \\ Rafael Guerrero ${ }^{3}$, Rubén Santiago Nicholls ${ }^{1,2}$ \\ 1 Laboratorio de Parasitología, Instituto Nacional de Salud, Bogotá, D.C., Colombia. \\ 2 Unidad de Parasitología, Departamento de Salud Pública y Tropical, Facultad de Medicina, Universidad \\ Nacional de Colombia, Bogotá, D.C., Colombia. \\ ${ }^{3}$ Gastroenterología Pediátrica, Universidad El Bosque, Bogotá, D.C., Colombia.
}

Se conocen investigaciones realizadas sobre la respuesta inmune humoral en giardiosis. Sin embargo, estudios sobre perfiles de antígenos de quistes y de trofozoítos de Giardia duodenalis reconocidos por $\lg G$ y subclases $\left(\lg _{1}, \lg G_{2}, \lg _{3}, \lg _{4}\right)$ anti-G. duodenalis no se han realizado en la misma magnitud. Con el fin de determinar los antígenos de los aislamientos colombianos de $G$. duodenalis reconocidos por IgG y sus subclases anti-G. duodenalis, se utilizó la metodología de Western blot. Quistes y trofozoítos del parásito, independientemente, se sometieron a separación de proteínas mediante SDS-PAGE. Las proteínas separadas fueron transferidas a membrana de nitrocelulosa mediante inmunoelectrotransferencia y su antigenicidad determinada confrontando éstas con IgG y sus subclases anti-G. duodenalis presentes en el suero de pacientes con giardiosis comprobada parasitológicamente. La unión antígeno-anticuerpo se detectó con conjugados anti-inmunoglobulina específicos unidos a fosfatasa alcalina, la cual permitió evidenciar los polipéptidos antigénicos cuando se adicionó el sustrato 5-bromo-4-cloro-3-indolil-fosfato/azul de nitrotetrazolio. Se leyeron y analizaron las bandas mediante análisis de regresión lineal, utilizando el programa Quantity One ${ }^{\circledR}$. Se reconocieron 32 antígenos, simultáneamente en quistes y trofozoítos de aislamientos colombianos del parásito por IgG total anti-G. duodenalis, que oscilaron entre 22-185 kDa y 19 en un rango de 42 a $180 \mathrm{kDa}$, reconocidos tanto por $\lg _{1}$ como por $\lg _{3}$ anti-G. duodenalis. Las $\operatorname{lgG}_{2}$ e $\operatorname{lgG}_{4}$ anti-parásito no reconocieron antígenos en ninguno de los dos estadios. Los antígenos de 27, 30, 31, 33, 45, 49, 57, 78, 89 y $170 \mathrm{kDa}$ son compartidos con aislamientos de G. duodenalis circulantes en otras regiones geográficas. El reconocimiento de antígenos de quistes y trofozoítos de los aislamientos colombianos de $G$. duodenalis por $\lg G$, $\lg _{1}$ e $\lg _{3}$ anti-G. duodenalis de pacientes infectados sugiere que los antígenos del parásito originan respuesta inmune humoral en el hospedero.

Palabras clave: giardiosis, antígenos, inmunoglobulina G, subclases de lgG, antígenos, inmunoelectrotransferencia.

Antigen identification of Giardia duodenalis Colombian isolates recognized by total IgG and its subclasses

Antigen profiles were described for Giardia duodenalis cysts and trophozoites that are recognized by $\lg G$ and its anti- $G$. dudodenalis subclasses $\left(\lg _{1}, \lg G_{2}, \lg G_{3}, \lg G_{4}\right)$. Antigens were identified by Western blot from $G$. duodenalis cyst and trophozoite isolates. Cysts and trophozoites were each subjected to protein separation by SDS-PAGE. The proteins were then transferred to nitrocellulose membranes by electroimmunoblot, and their antigenicity was determined by exposing them to sera from patients with confirmed diagnosis of $G$. duodenalis infection. The antigen-antibody reaction was revealed by specific alkaline phosphatase antibody conjugates against $\lg _{1}, \lg G_{2}, \lg G_{3}, \lg _{4}$ bands were visualized by addition of the substrate 5-bromo-4chloro-3-indolyl-phosphate and the stain nitro blue tetrazolium. The bands were read and analyzed by linear regression using Quantity One ${ }^{\circledR}$ software. Thirty two antigens were simultaneously recognized by total $\lg G$ anti-G. duodenalis in the cyst and trophozoite stages. 
The antigens varyied in molecular weight from 22 to $185 \mathrm{kDa}$. Nineteen antigens were identified by both $\operatorname{lgG}_{1}$ and $\operatorname{lgG}_{3}$ anti- $G$. duodenalis, with molecular weights ranging from 42 to $180 \mathrm{kDa}$. $\lg _{2}$ and $\lg G_{4}$ did not identify any antigen in either stage. The antigens of molecular weights 27 , $30,31,33,45,49,57,78,89$ and $170 \mathrm{kDa}$ are shared with $\mathrm{G}$. duodenalis isolates from other geographical regions of Colombia. The recognition of cyst and trophozoite antigens of Colombian G. duodenalis isolates by $\lg G, \lg _{1}$ and $\lg _{3}$ anti- $G$. duodenalis suggested that they are involved in the induction of the host immune response.

Key words: giardiasis, antigens, IgG, IgG subclasses, antigenic determinants, Western blot.

La giardiosis es la infección intestinal causada por el protozoo flagelado Giardia lamblia, también conocido como Giardia intestinales o Giardia duodenalis, la cual puede afectar al humano y producir comensalismo en mamíferos, reptiles y aves (1). La mayoría de las infecciones humanas causadas por G. duodenalis son asintomáticas; cuando no lo son se encuentran asociadas con diarrea, dolor abdominal, flatulencia y, en algunos casos, con síndrome de malabsorción (2). El humano desarrolla respuesta inmune humoral y celular a la infección por el parásito. Sin embargo, la protección inmune no ha sido demostrada conclusivamente en la giardiosis humana (3).

La respuesta inmune en giardiosis ha sido demostrada por evidencias tales como: 1) la autolimitación de la infección; 2) la participación de monocitos citotóxicos en la modulación de la respuesta inmune; 3) los pacientes inmunocomprometidos son más susceptibles a la infección, especialmente aquéllos con hipogammaglobulinemia; 4) en áreas endémicas, las personas que las habitan son menos susceptibles a la infección que los visitantes; 5) las infecciones crónicas en animales atímicos o tratados con medicamentos inmunosopresores, y 6) la detección de anticuerpos anti-G. duodenalis en suero de pacientes infectados por $G$. duodenalis (2).

Las investigaciones serológicas en giardiosis han demostrado ventajas prácticas en el diagnóstico debido a que los anticuerpos específicos contra

\footnotetext{
Correspondencia:

Sofía Duque, Laboratorio de Parasitología, Instituto Nacional de Salud, Avenida Calle 26 No 51-60, Bogotá, D.C., Colombia Teléfono: 2207700, extensión 455; Fax :2200901 sduque@ins.gov.co

Recibido: 20/11/02; aceptado: 23/05/03
}

G. duodenalis se detectan en pacientes asintomáticos, sintomáticos y en pacientes con excreción intermitente de quistes (4). Así, estudios previos demuestran que después de una infección se producen anticuerpos; los de IgM son los primeros en aparecer y se mantienen elevados entre dos y tres semanas (5). Los anticuerpos IgA permanecen elevados aún después de haberse tratado la infección (6) y los anticuerpos IgG se detectan en el $80 \%$ de los pacientes, respuesta que puede persistir por largos períodos (7).

Diferentes grupos de investigadores han tratado de identificar antígenos de G. duodenalis reconocidos por anticuerpos específicos (8). Uno de ellos analizó 4 aislamientos de $G$. duodenalis cultivados in vitro, provenientes de humanos de varias regiones geográficas, mediante electroforesis en gel de poliacrilamida (SDSPAGE) sin encontrar diferencias significativas entre ellos. Sin embargo, al confrontar los antígenos reconocidos por los anticuerpos presentes en los sueros humanos mediante ELISA, observaron que la respuesta humoral estaba dirigida a antígenos específicos y que existía variabilidad genética entre los aislamientos de G. duodenalis.

La variación antigénica en giardiosis ha sido demostrada in vitro (9) e in vivo (10). La mayoría de los estudios han utilizado el aislamiento WB de $G$. duodenalis proveniente de pacientes sintomáticos de Afganistán y han demostrado que la variación antigénica ocurre frecuentemente en la superficie de los trofozoítos de aislamientos de $G$. duodenalis $(1,11)$.

Igualmente se ha informado que los antígenos de G. duodenalis más frecuentemente involucrados en el desarrollo de estos anticuerpos poseen pesos moleculares de 30, 57, 82, 88 y $170 \mathrm{kDa}$. 
Muchos de éstos corresponden a proteínas de la superficie o a estructuras del disco ventral y del citoesqueleto de G. duodenalis (12). En 1993, Hill recomendó realizar estudios para analizar el papel de estos antígenos en la inmunidad o en la infección por $G$. duodenalis (13).

El conocimiento de la composición de los antígenos del parásito y el papel que juegan en la respuesta inmune durante la infección en giardiosis sería importante para comprender la patogénesis de la enfermedad. Igualmente, la identificación de antígenos reconocidos por el sistema inmune del hospedero es de interés para entender la modulación de la infección por $G$. duodenalis (14).

No se conocen los antígenos de quistes y trofozoítos de aislamientos colombianos de $G$. duodenalis reconocidos por IgG y subclases anti$G$. duodenalis de pacientes con giardiosis comprobada parasitológicamente. El presente estudio se realizó con la finalidad de identificar los antígenos de aislamientos colombianos de $G$. duodenalis estimuladores del desarrollo de la lgG y sus subclases.

\section{Materiales y métodos}

\section{Sueros}

Las 161 muestras de suero humano utilizadas en el estudio fueron suministradas por el banco de muestras del Laboratorio de Parasitología del Instituto Nacional de Salud (INS). A las muestras de suero se les había determinado, previamente, la ausencia de anticuerpos anti-Entamoeba histolytica mediante inmunodifusión (14) y la presencia o ausencia de $\lg G$ anti-G. duodenalis por ELISA (15).

Los sueros se clasificaron de la siguiente manera:

Grupo A. Controles positivos: 72 sueros de pacientes con giardiosis comprobada parasitológicamente por medio de la visualización de quistes o trofozoítos del parásito y por la presencia de lgG anti- $G$. duodenalis en suero.

Grupo B. 20 sueros de pacientes con sospecha clínica de giardiosis y positivos parasitológicamente con parásitos intestinales diferentes a $G$. duodenalis y con presencia de IgG anti-G. duodenalis en suero. A estos pacientes se les confirmó parasitológicamente la ausencia de quistes o trofozoítos de $G$. duodenalis y la presencia de Endolimax nana, Blastocystis hominis, lodamoeba butschlii, Entamoeba coli, complejo Entamoeba histolytica/Entamoeba dispar, Trichomonas hominis y uncinarias, y serológicamente por inmunodifusión, la ausencia de anticuerpos anti-Entamoeba histolytica y por ELISA la presencia de anti-G. duodenalis.

Grupo C. Controles negativos: 69 sueros de pacientes sin giardiosis sometidos a pruebas parasitológicas y serológicas para confirmar la ausencia de $G$. duodenalis y otros parásitos intestinales en meconio de neonatos y heces de adulto y sin detección de IgG anti-G. duodenalis en suero.

Los controles negativos se dividieron en dos subgrupos: uno con 49 muestras de cordón umbilical de neonatos, recién cortado y eliminado, de diferentes edades gestacionales y otro con 20 sueros de adultos sin giardiosis.

\section{Quistes y trofozoítos de Giardia duodenalis}

Una mezcla de quistes y uno de trofozoítos de $G$. duodenalis de 24 aislamientos se obtuvieron del banco de muestras del Laboratorio de Parasitología del INS. Cada mezcla había sido previamente elaborada con una población de $5 \times 10^{6}$ parásitos/ ml en solución reguladora de fosfatos (PBS) (15).

\section{Preparación de antígeno de quistes y trofozoítos de Giardia duodenalis}

Los quistes y trofozoítos del parásito se congelaron de manera independiente a $-196{ }^{\circ} \mathrm{C}$ y se descongelaron a temperatura ambiente mediante agitación vórtex. La congelación y descongelación se realizó 3 veces consecutivas. Se centrifugaron a $2.000 \mathrm{~g} / 4^{\circ} \mathrm{C}$ por 10 minutos y se conservó el sobrenadante (antígeno). La concentración de proteínas existente en el antígeno se determinó mediante el método de Bradford (16).

\section{Separación de proteínas de quistes y trofozoítos de giardia mediante electroforesis en gel de poliacrilamida (SDS-PAGE)}

Se realizó, de forma independiente, la separación de proteínas de los estadios según el método 
descrito por Laemmli, 1970 (17), así: se elaboró un gel concentrador y uno separador de poliacrilamida en concentraciones de $4 \%$ y $10 \%$, respectivamente. Se adicionaron a los geles los marcadores de peso molecular y las diluciones de antígeno de quistes y trofozoítos, tanto en ausencia como en presencia de 2-mercaptoetanol (2-ME), en un rango de 0,4-1,2 $\mathrm{mg} / \mathrm{ml}$. Se realizó la electroforesis a $18^{\circ} \mathrm{C} / 35 \mathrm{~mA} / 75$ voltios $/ 3$ vatios de potencia por 1 hora y 10 minutos. Se colorearon los geles con azul de Coomasie por 1 minuto. El exceso de colorante se retiró sumergiendo los geles en solución decoloradora de etanol-ácido acético (3:1).

\section{Identificación de antígenos de quistes y trofozoítos de Giardia duodenalis mediante inmunoelectrotransferencia}

El reconocimiento de antígenos de quiste y trofozoíto de $G$. duodenalis se realizó mediante el procedimiento descrito por Towbin et al. (18).

Se transfirieron las proteínas de quistes y trofozoítos separadas mediante SDS-PAGE a una membrana de nitrocelulosa (MNC) a $4{ }^{\circ} \mathrm{C} / 200 \mathrm{~mA} /$ 130 voltios/26 vatios por 2 horas. Se verificó la transferencia de las proteínas coloreando la MNC con rojo Ponceau S. Se observó que la concentración de $0,8 \mathrm{mg} / \mathrm{ml}$ de proteína de quiste y de trofozoíto era la óptima cuando se confrontaba con IgG total anti- $G$. duodenalis y de $1,2 \mathrm{mg} / \mathrm{ml}$ cuando se enfrentaba con $\lg _{1}, \lg _{2}$, $\lg _{3}$ e $\lg _{4}$ anti-G.duodenalis.

Se bloqueó la MNC a $18^{\circ} \mathrm{C}$ por 1 hora con leche descremada al $4 \%$ disuelta en solución reguladora de fosfatos más Tween 20 al 0,1\% (PBS-T) y se lavó 3 veces con PBS-T por 5 minutos cada vez.

Se agregaron a la MNC diluciones de las muestras de suero de pacientes para el reconocimiento de antígenos de quistes y trofozoítos por lgG total anti-G. duodenalis y de las subclases de lgG. Las muestras se incubaron a $18{ }^{\circ} \mathrm{C}$ por 18 horas. La dilución óptima de suero fue de 1:100 para IgG total y de 1:20 para las subclases de lgG. Se lavó la MNC como se describió anteriormente. Se incubó la MNC a $18^{\circ} \mathrm{C}$ por 1 hora a temperatura ambiente con una dilución 1:500 y 1:250 de anti$\lg G$ y anti- $\lg G_{1}, \lg G_{2}, \lg G_{3}$ e $\lg G_{4}$ humana unida a fosfatasa alcalina (Bio-Rad), respectivamente. Se lavó la MNC 2 veces con PBS-T y una vez con solución reguladora Tris- $\mathrm{NaCl}-\mathrm{MgCl}$. Se reveló la reacción con 5-bromo-4-cloro-3-indol-fosfato (BCIP) y azul de nitrotetrazolio (NBT).

\section{Análisis de resultados}

Se realizó la lectura y análisis de las bandas utilizando el programa Quantity One ${ }^{\circledR}$, mediante análisis de regresión lineal para determinar el perfil de proteínas de quistes y de trofozoítos de aislamientos colombianos de $G$. duodenalis y el perfil de antígenos de quistes y de trofozoítos de aislamientos de $G$. duodenalis reconocidos por IgG total y las subclases de lgG anti-G. duodenalis de pacientes con giardiosis comprobada parasitológicamente.

A partir del perfil de antígenos de quistes y de trofozoítos de aislamientos del parásito reconocidos por lgG total y las susbclases de lgG anti-G. duodenalis, se establecieron las frecuencias de reconocimiento de cada uno de los antígenos y el número de antígenos reconocidos simultáneamente.

\section{Resultados}

\section{Discriminación diagnóstica de antígenos de quistes y trofozoítos}

Pacientes con giardiosis comprobada parasitológicamente. Se reconocieron 33, 27 y 23 antígenos en quistes de aislamientos colombianos de $G$. duodenalis por $\lg G$ total, $\lg G_{1}$ e $\lg G_{3}$ anti- $G$. duodenalis, respectivamente (figura 1, cuadro 1).

Se reconocieron 33, 24 y 21 antígenos en trofozoítos de aislamientos colombianos de $G$. duodenalis, por $\lg G$ total, $\lg _{1}$ e $\lg _{3}$ anti- $G$. duodenalis, respectivamente (figura 1, cuadro 1).

Ningún antígeno en ninguno de los dos estadios del parásito fue reconocido por $\lg _{2}$ e $\lg _{4}$.

Los antígenos de 22, 23, 26,27, 30, 31, 33, 35, $38,42,43,45,49,52,57,60,62,65,68,72,75$, $78,82,89,99,110,133,145,155,170,180$ y 185 $\mathrm{kDa}$ fueron reconocidos por $\lg G$ total anti- $G$. duodenalis tanto en quistes como en trofozoítos de los aislamientos colombianos del parásito (figura 1, cuadro 1). 
Los polipéptidos antigénicos de 42, 43, 49, 52, $57,60,62,65,68,75,78,82,89,99,110,133$, 145,170 y $180 \mathrm{kDa}$ fueron reconocidos, simultáneamente, por las subclases $\lg _{1}$ e $\lg _{3}$ anti-G. duodenalis en quistes y trofozoítos de los aislamientos del parásito (figura 1, cuadro 1).

Pacientes con sospecha clínica de giardiosis, otras parasitosis intestinales y presencia de lgG y subclases de IgG ANTI-G. duodenalis. Se reconocieron antígenos de quistes y trofozoítos de $G$. duodenalis de pesos moleculares entre 25$241 \mathrm{kDa}$ por IgG total, $\lg _{1}$ e $\operatorname{lgG}_{3}$ anti- $G$. duodenalis (figura 1, cuadro 1).

Las IgG total, $\lg G_{1}$ e $\lg _{3}$ anti-G. duodenalis reconocieron 22, 12 y 16 antígenos de quistes de aislamientos del parásito, respectivamente. Estas mismas inmunoglobulinas reconocieron 20, 22 y 16 antígenos en trofozoítos de los aislamientos nativos del parásito, respectivamente (figura 1, cuadro 1).

Pacientes sin giardiosis. En el grupo de 49 neonatos utilizados como controles negativos ningún antígeno de quistes ni de trofozoítos de
G. duodenalis fue reconocido por anticuerpos $\lg G$ y subclases anti-parásito (figura 1).

En los sueros de los controles negativos provenientes del subgrupo de adultos, la IgG total reconoció antígenos de 38, 82, 99, 155, 200 y $241 \mathrm{kDa}$ y sus subclases $\operatorname{lgG}_{1}$ e $\operatorname{lgG}_{3}$ reconocieron los de 38,82 y $200 \mathrm{kDa}$ y el de $200 \mathrm{kDa}$, respectivamente (figura 1 ).

Los antígenos de 82 y $200 \mathrm{kDa}$ fueron reconocidos en trofozoítos por lgG total, en tanto las subclases $\lg _{1}$ e $\lg G_{3}$ no reconocieron ningún antígeno en este estadio (figura 1).

\section{Frecuencia de reconocimiento de antígenos ( $k D a)$ de quistes y trofozoítos por IgG y subclases de lg G de pacientes con giardiosis comprobada parasitológicamente}

Las frecuencias de reconocimiento fueron entendidas como el resultado porcentual del número total de sueros con presencia de anticuerpos anti-G. duodenalis (numerador) y el número de ellos que reconocieron un determinado antígeno (denominador).

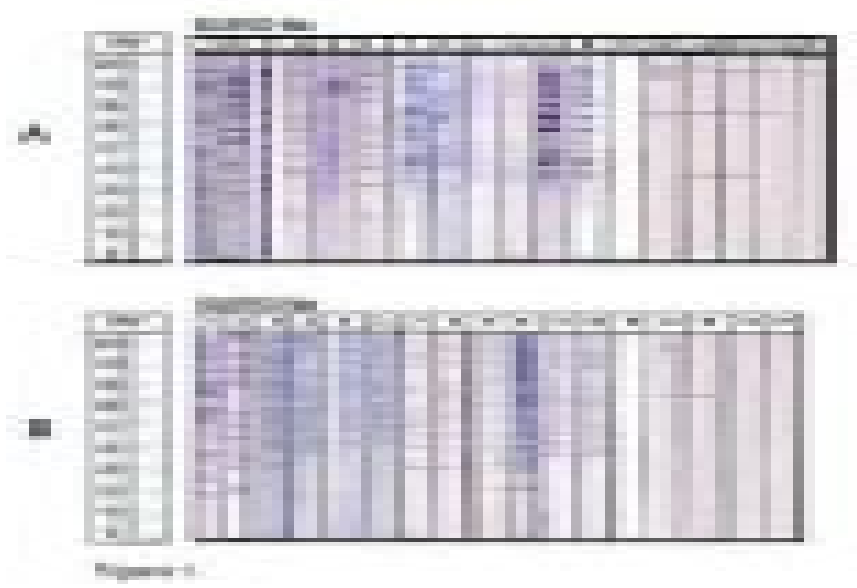

Figura 1. Discriminación diagnóstica.

A. Antígenos de quistes de Giardia duodenalis reconocidos por $\lg G$ total, $\lg _{1}$ e $\lg _{3}$ anti- $G$. duodenalis. Grupo $A$, carriles 1-2, antígenos reconocidos por $\lg G$ total; $3-4$, antígenos reconocidos por $\lg _{1} ; 5-6$, antígenos reconocidos por $\lg G_{3}$. $G_{r u p o}$ $\mathrm{B}$, carriles 7-8, antígenos reconocidos por IgG total; 9-10, antígenos reconocidos por $\lg _{1} ; 11-12$, antígenos reconocidos por $\operatorname{lgG}_{3}$. Grupo C, neonatos, carril 13, antígenos reconocidos por $\operatorname{lgG}$ total, $\lg _{1}$ e $\operatorname{lgG}_{3}$; adultos, carriles 14-15, antígenos reconocidos por IgG total; $16-17$, antígenos reconocidos por $\lg _{1} ; 18$, antígenos reconocidos por $\operatorname{lgG}_{3}$.

B. Antígenos de trofozoítos de Giardia duodenalis reconocidos por $\lg G$ total, $\lg _{1}$ e $\lg G_{3}$ anti-G. duodenalis. Grupo $A$, carriles 1-2, antígenos reconocidos por $\lg G$ total; 3-4, antígenos reconocidos por $\lg _{1} ; 5-6$, antígenos reconocidos por $\lg G_{3}$. Grupo $B$, carriles 7-8, antígenos reconocidos por IgG total; 9-10, antígenos reconocidos por $\lg \mathrm{G}_{1} ; 11$-12, antígenos reconocidos por $\operatorname{lgG}_{3}$. Grupo $C$, neonatos, carril 13, antígenos reconocidos por $\operatorname{lgG}$ total, $\lg _{1}$ e $\operatorname{lgG}_{3}$; adultos, carriles 14-15, antígenos reconocidos por $\lg G$ total; 16 , antígenos reconocidos por $\lg _{1} ; 17$, antígenos reconocidos por $\lg _{3}$. 
Las frecuencias de reconocimiento de antígenos de quistes por $\lg G$ total, $\lg G_{1}$ e $\lg _{3}$ oscilaron en un rango de $1 \%$ a $65 \%$, de $1 \%$ a $71 \%$ y de $1 \%$ a$72 \%$, respectivamente (cuadro 1 ). Estas frecuencias para el caso de los trofozoítos en este mismo grupo de inmunoglobulinas fueron de $1 \%$ a $47 \%$, de $1 \%$ a $68 \%$ y de $1 \%$ a $85 \%$, respectivamente (cuadro 1).

Cuadro 1. Antígenos de quistes $(Q)$ y trofozoítos $(T)$ reconocidos por $\lg G$ total $\left(\lg _{T}\right)$, $\lg G_{1}$ e $\lg G_{3}$ anti-G. duodenalis y sus frecuencias de reconocimiento por los sueros de los pacientes de los grupos A y B.

\begin{tabular}{|c|c|c|c|c|c|c|c|c|c|c|c|c|}
\hline \multirow{3}{*}{$\begin{array}{l}\text { ANTIGENO } \\
\text { P M } \\
\text { Kda }\end{array}$} & \multicolumn{6}{|c|}{ GRUPO A } & \multicolumn{6}{|c|}{ GRUPOB } \\
\hline & \multicolumn{2}{|c|}{ IgGT \% } & \multicolumn{2}{|c|}{$\lg G_{1} \%$} & \multicolumn{2}{|c|}{$\lg _{3} \%$} & \multicolumn{2}{|c|}{ IgGT \% } & \multicolumn{2}{|c|}{$\lg G_{1} \%$} & \multicolumn{2}{|c|}{$\operatorname{lgG}_{3} \%$} \\
\hline & $\mathbf{Q}$ & $\mathbf{T}$ & $\mathbf{Q}$ & $\mathbf{T}$ & $\mathbf{Q}$ & $\mathbf{T}$ & $\mathbf{Q}$ & $\mathbf{T}$ & $\mathbf{Q}$ & $\mathbf{T}$ & $\mathbf{Q}$ & $\mathbf{T}$ \\
\hline 20 & & 4 & & & & & & & & & & \\
\hline 22 & 1 & 3 & & & & & & & & & & \\
\hline 23 & 3 & 6 & & & & & & & & & & \\
\hline 25 & & & & & 5 & & & & & 5 & & \\
\hline 26 & 1 & 3 & & & & & & & & 5 & & \\
\hline 27 & 1 & 11 & 1 & & & & & & & & & \\
\hline 29 & 4 & & & & & & & & & & & \\
\hline 30 & 6 & 4 & 1 & & & & 15 & 5 & & 15 & & \\
\hline 31 & 11 & 13 & 1 & 1 & & & & & & 5 & & \\
\hline 33 & 7 & 1 & & & & & 15 & 20 & & 15 & & \\
\hline 35 & 11 & 15 & 6 & 4 & 1 & & 5 & & & 5 & & 30 \\
\hline 38 & 10 & 26 & 10 & 1 & & & 15 & 10 & 10 & 5 & 25 & \\
\hline 40 & & & & & & & & 15 & 5 & 30 & 25 & \\
\hline 42 & 15 & 11 & 22 & 1 & 3 & 3 & & & & & & \\
\hline 43 & 28 & 10 & 15 & 29 & 25 & 6 & 5 & & 65 & 20 & 30 & 40 \\
\hline 45 & 11 & 18 & 19 & 7 & 7 & & 5 & 20 & 15 & 35 & 25 & 50 \\
\hline 48 & & & & & & & & & & & & 5 \\
\hline 49 & 31 & 24 & 35 & 33 & 14 & 11 & 20 & 10 & 5 & 40 & 15 & \\
\hline 52 & 29 & 42 & 28 & 39 & 39 & 74 & 10 & 10 & & 55 & 20 & \\
\hline 57 & 31 & 25 & 18 & 26 & 33 & 4 & 30 & 10 & 20 & 45 & 35 & 55 \\
\hline 60 & 17 & 22 & 13 & 28 & 11 & 19 & & 30 & & & & \\
\hline 62 & 26 & 18 & 25 & 19 & 56 & 65 & 5 & 25 & 5 & & 15 & 5 \\
\hline 65 & 22 & 47 & 24 & 24 & 26 & 10 & & & & 50 & & 45 \\
\hline 68 & 8 & 19 & 8 & 1 & 1 & 10 & & & & & & \\
\hline 69 & & & & & & & 10 & & & 35 & 10 & 30 \\
\hline 72 & 10 & 38 & 17 & 11 & 13 & & & & & & & \\
\hline 74 & & & & & & & & & & 20 & & 10 \\
\hline 75 & 17 & 13 & 22 & 24 & 33 & 14 & 10 & 30 & & & 35 & \\
\hline 78 & 8 & 18 & 26 & 43 & 18 & 57 & 10 & 5 & 65 & 50 & & 15 \\
\hline 82 & 22 & 10 & 24 & 7 & 14 & 11 & 20 & 25 & & & & \\
\hline 89 & 11 & 24 & 19 & 13 & 29 & 3 & & & & & & \\
\hline 94 & & & & & & & & & & 25 & & \\
\hline 99 & 24 & 32 & 32 & 57 & 43 & 28 & 15 & 20 & & 40 & 20 & 100 \\
\hline 105 & & & & & & & & & & 25 & & \\
\hline 110 & 57 & 13 & 38 & 19 & 44 & 58 & 25 & 35 & 85 & & 45 & \\
\hline 129 & & & & & & & & & & 55 & & 45 \\
\hline 133 & 28 & 40 & 31 & 6 & 32 & 1 & 30 & 30 & & & & \\
\hline 145 & 50 & 29 & 47 & 68 & 53 & 85 & 15 & 5 & 75 & 15 & 50 & 45 \\
\hline 155 & 8 & 7 & 21 & & 17 & 1 & 40 & 60 & & 75 & 25 & 60 \\
\hline 170 & 65 & 33 & 25 & 4 & 28 & 14 & & & & & & \\
\hline 180 & 36 & 33 & 71 & 38 & 72 & 69 & 60 & 25 & 100 & & 70 & \\
\hline 185 & 40 & 38 & & & & 1 & 10 & 55 & 75 & & 55 & \\
\hline 200 & & & & & & & & & & & & \\
\hline 220 & & & & & & & & & & & & 10 \\
\hline 241 & & & & & & & & & & & & 45 \\
\hline Total & 33 & 33 & 27 & 24 & 23 & 21 & 22 & 20 & 12 & 22 & 16 & 16 \\
\hline
\end{tabular}


Frecuencia de reconocimiento de antígenos de quistes. La IgG anti-G. duodenalis reconoció los antígenos de 110,145 y $170 \mathrm{kDa}$ en $57 \%, 50 \%$ y $65 \%$, respectivamente. Treinta polipéptidos antigénicos del total de los 33 identificados por la inmunoglobulina fueron reconocidos entre $1 \%$ y $40 \%$.

La subclase $\lg G_{1}$ reconoció el antígeno de 145 $\mathrm{kDa}$ en el $47 \%$ y el de $180 \mathrm{kDa}$ en el $71 \%$. Veinticinco antígenos de los 27 identificados por la inmunoglobulina fueron reconocidos entre $1 \%$ y $38 \%$.

La $\lg \mathrm{G}_{3}$ reconoció los antígenos de 62, 99, 110 , 145 y $180 \mathrm{kDa}$ en el $56 \%, 43 \%, 44 \%, 53 \%$ y $72 \%$, respectivamente. Dieciocho de los 23 antígenos identificados por la inmunoglobulina fueron reconocidos entre $1 \%$ y $39 \%$.

Ningún antígeno fue reconocido en quiste con una frecuencia igual o superior al $80 \%$.

Frecuencia de reconocimiento de antígenos de trofozoítos. La IgG anti-G. duodenalis reconoció el antígeno de $52 \mathrm{kDa}$ en el $42 \%$ y el de $65 \mathrm{kDa}$ en el $47 \%$. Treinta y uno de los 33 antígenos identificados por la inmunoglobulina fueron reconocidos entre el $1 \%$ y el $40 \%$.

La $\lg G_{1}$ reconoció los antígenos de 78, 99 y 145 $\mathrm{kDa}$ en el $43 \%, 57 \%$ y $68 \%$, respectivamente. La inmunoglobulina no reconoció antígenos con frecuencias mayores del $80 \%$.

La lg $\mathrm{G}_{3}$ reconoció polipéptidos antigénicos de 52 , $62,78,110$ y $145 \mathrm{kDa}$ en el $74 \%, 65 \%, 57 \%$, $58 \%$ y $85 \%$, respectivamente. La inmunoglobulina tan sólo reconoció un antígeno en el $85 \%$.

\section{Número de antígenos de quistes y trofozoítos reconocidos simultáneamente por IgG $y$ subclases anti-G. duodenalis de pacientes con giardiosis comprobada parasitológicamente}

El número de antígenos de quistes reconocidos simultáneamente por IgG total, lgG1 e lgG3 varió de 1 a 12 , de 3 a 10 y de 1 a 11 , respectivamente (figura 2).

El número de polipéptidos antigénicos de trofozoítos reconocidos simultáneamente por lgG total, IgG1 e lgG3 varió de 1 a 15, de 1 a 8 y de 1 a 10 , respectivamente (figura 3 ).

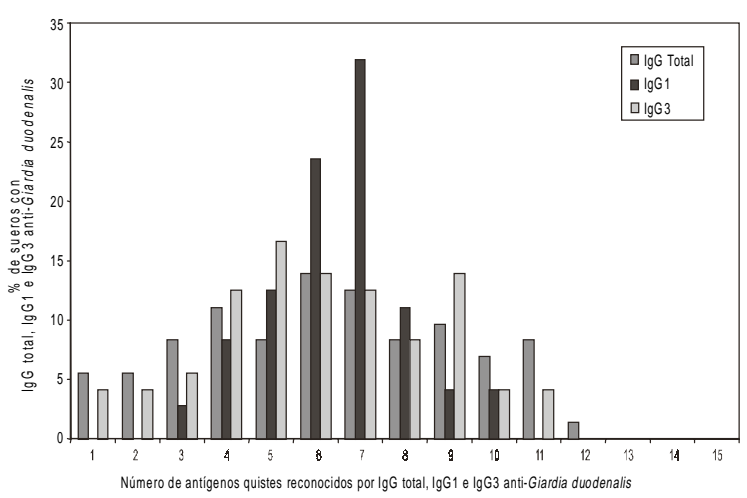

Figura 2. Comparación del número de antígenos de quistes de Giardia duodenalis reconocidos por lgG total, $\lg _{1}$ e $\lg _{3}$ de pacientes con giardiosis comprobada parasitológicamente.

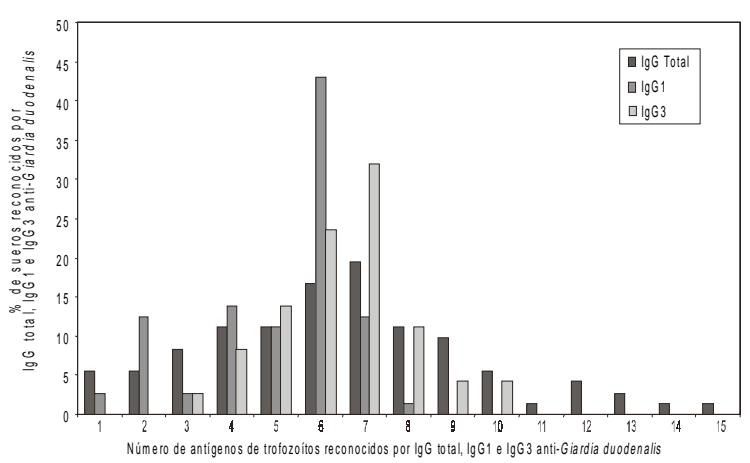

Figura 3. Comparación del número de antígenos de trofozoítos de Giardia duodenalis reconocidos por lgG total, $\lg _{1}$ e $\lg _{3}$ de pacientes con giardiosis comprobada parasitológicamente.

El mínimo de antígenos reconocidos simultáneamente por IgG total en quistes y trofozoítos fue de 1 y el máximo de 12 y 15, respectivamente.

Un mínimo de 3 y 1 y un máximo de 10 y 8 polipéptidos antigénicos de quistes y trofozoítos, respectivamente, fueron identificados simultáneamente por $\lg G_{1}$.

El mínimo de antígenos reconocidos simultáneamente en quistes y trofozoítos por $\lg _{3}$ fue de 1 y 3 y el máximo de 11 y 10, respectivamente.

\section{Discusión}

Las $\lg G$ total, $\lg G_{1}$ e $\lg G_{3}$ reconocieron antígenos de quistes y trofozoítos, en tanto que las subclases $\lg _{2}$ e $\lg _{4}$ no reconocieron ningún polipéptido antigénico. 
Los antígenos de G. duodenalis fueron realmente reconocidos por inmunoglobulinas anti-G. duodenalis, lo que puede señalarse porque la especificidad del Western blot utilizado en el estudio quedó demostrada por la confirmación parasitológica de la ausencia de $G$. duodenalis y otros parásitos intestinales en meconio de neonatos y en heces de adultos sanos y la confirmación serológica de la no detección de lgG total anti-G. duodenalis en muestras de neonato $\mathrm{y}$ de adultos sin giardiosis.

Adicionalmente, no sería prudente afirmar que los antígenos del parásito reconocidos por sueros de pacientes con otras parasitosis intestinales y sospecha clínica de giardiosis sean inespecíficos. Esto porque, aunque parasitológicamente no se hubiesen observado quistes o trofozoítos de $G$. duodenalis en las heces de los pacientes, no se puede asegurar que no hubiesen estado en contacto con el parásito en algún momento de su vida y desarrollado anticuerpos anti-G. duodenalis, como se confirmó serológicamente. Aún más, se conoce que $E$. histolytica puede ser invasivo en el hospedero y $G$. duodenalis puede estar en contacto con el huésped en el intestino delgado. Por ello, son parásitos intestinales que pueden inducir respuesta humoral en el hospedero $(19,20)$. En cambio E. coli, E. nana, I. butschlii, T. hominis, uncinarias y $B$. hominis no inducen respuesta inmune $y$, por ende, ninguna producción de anticuerpos (21).

La IgG total reconoció antígenos de quistes y trofozoítos utilizando concentraciones de $0,8 \mathrm{mg} /$ $\mathrm{ml}$, que es equivalente a $16 \mathrm{mg} / 20 \mathrm{ml}$ al adicionado a cada carril del gel de poliacrilamida. Esta concentración es mayor en $6 \mathrm{mg} / \mathrm{ml}$ y menor en $24 \mathrm{mg} / \mathrm{ml}$ a las utilizadas por Janoff et al. (22), Soliman et al. (23) y Taylor y Wenman (24), respectivamente.

Los antígenos, independientemente del estadio, cualitativamente presentaron heterogeneidad en la tonalidad de coloración. Esto se debió, quizás, a las diferencias que puedan existir en avidez y afinidad de los anticuerpos presentes en el suero del hospedero. Se conoce que la unión antígenoanticuerpo es una función tanto de la avidez como de la concentración del anticuerpo $(25,26)$.
La IgG total reconoció 33 antígenos tanto en quistes como en trofozoítos. El antígeno de 29 kDa sólo fue reconocido en quistes y es propio de la pared (27) y el de $20 \mathrm{kDa}$ es parte del citoesqueleto, estructura propia de los trofozoítos (28).

Erlandsen et al. informaron antígenos de 29, 75, 88 y $102 \mathrm{kDa}$ detectados por anticuerpos policlonales, desarrollados en conejos contra quistes de Giardia muris (27). Faubert (11), corroboró los hallazgos de Gillin et al. (29), quienes identificaron antígenos de quistes de G. duodenalis de 21, 28, 36 y 49 kDa, también reconocidos por anticuerpos policlonales desarrollados en conejo.

En los aislamientos colombianos de G. duodenalis los antígenos del parásito fueron reconocidos por IgG anti-G duodenalis detectada en suero humano. El antígeno de $29 \mathrm{kDa}$ sólo fue reconocido en quistes, los de 49 y $75 \mathrm{kDa}$ en quistes y trofozoítos y los de 88 y $102 \mathrm{kDa}$ en ninguno de los estadios. Se ha informado que el quiste da origen al trofozoíto, quizá por ello el antígeno de 75 kDa y, muy probablemente (aunque aún sin confirmar en la literatura científica), el de $49 \mathrm{kDa}$ sean identificados en ambos estadios. Se conoce por los estudios de localización ultraestructural que los antígenos de 29, 75, 88 y 102 kDa se encuentran asociados con los filamentos de la superficie externa de los quistes y con los filamentos estructurales de los trofozoítos en su proceso de enquistamiento (27).

Los antígenos de trofozoítos que fueron reconocidos por IgG total, con pesos moleculares de $20,22,23,26,35,38,42,43,52,60,62,65$, $68,72,75,99,110,133,145,155,180$ y 185 $\mathrm{kDa}$, todavía no han sido reconocidos en aislamientos de $G$. duodenalis circulantes en otras regiones geográficas. Ello sugiere la variabilidad que existe entre los diferentes aislamientos de $G$. duodenalis (30).

Bienz et al. (31) infomaron que durante la infección G. duodenalis sufre variación antigénica y la habilidad del parásito para alterar las proteínas antigénicas de superficie se ha demostrado en varios estudios. Aún más, la composición y complejidad de aislamientos de G. duodenalis 
pueden estar asociadas con aspectos de la relación hospedero-parásito (32).

Antígenos de trofozoítos del parásito han sido reconocidos por IgG total. Así, los de 27, 31 y 33 $\mathrm{kDa}$ han sido informados por Taylor y Wenman (24); el de $30 \mathrm{kDa}$ por Janoff et al. (22); los de 30, $31,57,89$ y $170 \mathrm{kDa}$ por Char et al. (33); los de 49 y $78 \mathrm{kDa}$ por Reiner y Gillin (34), y los de 31, 45 $\mathrm{kDa}$ y $170 \mathrm{kDa}$ por Char et al. (35). Ello permite inferir que los antígenos de trofozoítos de aislamientos colombianos de $G$. duodenalis de 27 , $30,31,33,45,49,57,78,89$ y $170 \mathrm{kDa}$ son compartidos con aislamientos de $G$. duodenalis circulantes en otras regiones geográficas.

Las subclases $\lg _{1}$ e $\operatorname{lgG}_{3}$ reconocieron, simultáneamente, 18 antígenos con pesos moleculares entre 42 y $180 \mathrm{kDa}$. El antígeno de 49 kDa es el único común con respecto a los siete, de $25,33,49,56,64,103$ y $113 \mathrm{kDa}$, identificados por las mismas inmunoglobulinas e informados por Soliman et al. (23). La IgG reconoció los polipéptidos antigénicos de 27 y $30 \mathrm{kDa}$ solamente en quistes y la $\operatorname{lgG}_{3}$ el de 185 kDa sólo en trofozoítos.

Se conoce que diferentes subgrupos de células $T$ producen citocinas que al parecer afectan la producción de subclases de inmunoglubilina $\mathrm{G}$. Así, los linfocitos $\mathrm{T}$ ayudadores $\mathrm{TH}_{2}$ producen interleucina 4 e inducen respuestas de tipo $\lg _{1}$ e $\lg _{3}(36)$. Las subclases de $\lg _{1}$ e $\lg G_{3}$ son las inmunoglobulinas que fácilmente fijan el complemento, y la $\lg _{3}$ es la más hábil en la fijación de éste, lo cual ha sido comprobado in vitro al observar la lisis de los trofozoítos de $G$. duodenalis $(37,38)$. La subclase $\lg _{1}$ se desarrolla como una respuesta a la presencia de antígenos polipeptídicos (39) y la $\operatorname{lgG}_{3}$ a antígenos que contienen carbohidratos, especialmente en bacterias patógenas (40). Algunos autores piensan que la lisis de protozoos y bacterias patógenas en el intestino puede ser mediada por la $\lg _{3}$, tal vez porque se ha comprobado in vitro que ésta aglutina trofozoítos del parásito, los cuales posteriormente son lisados en presencia del complemento $(23,37,38)$.

Quizá el reconocimiento de los antígenos de 27, 30 y $31 \mathrm{kDa}$ por $\lg \mathrm{G}_{1}$ e $\lg \mathrm{G}_{3}$ se deba a su mayor antigenicidad que estimula aún más a los linfocitos
$\mathrm{TH}_{2}$ para el desarrollo de $\lg \mathrm{G}_{1}$ e $\lg \mathrm{G}_{3}$ anti-Giardia. Las subclases $\lg _{2}$ e $\lg G_{4}$, cuya respuesta está regulada por interferón gamma producido por los linfocitos T ayudadores, $\mathrm{TH}_{1}(36)$, y que tienen una menor capacidad de fijar el complemento (41), no reconocieron antígenos ni en quistes ni en trofozoítos. En 1998, Soliman et al. (23) no confrontaron anticuerpos $\lg _{2}$ e $\operatorname{lgG}_{4}$ anti-Giardia en suero con el trofozoíto del parásito para detectar proteínas antigénicas.

Las $\lg G$ total, $\lg G_{1}$ e $\lg G_{3}$ reconocieron antígenos de bajo y alto peso molecular en ambos estadios de los aislamientos. Estudios de otros autores informan que constituyen parte de la superficie de los trofozoítos del parásito los antígenos de 29 y $75 \mathrm{kDa}$ (42), 30, 38 y $180 \mathrm{kDa}(43), 31$ y 33 kDa $(22,24), 49$ kDa (44), y 170 kDa (12). Los polipéptidos antigénicos localizados en el flagelo de los trofozoítos han sido los de $30 \mathrm{kDa}(28)$, 155 y $170 \mathrm{kDa}$ (45). Los antígenos que se han encontrado en el citoesqueleto son los de 29, 30, 31 y 60 kDa (28), 155 y 170 kDa (45); el grupo entre 30-33 kDa es característico de las giardinas que se encuentran en el disco ventral. El antígeno de $57 \mathrm{kDa}$ (33) conforma el citosol, el de $49 \mathrm{kDa}$ (34) es un antígeno constitutivo, el de $65 \mathrm{kDa}$ (46) es antígeno de excreción/secreción y el de 78 kDa (34), un antígeno regulador.

Los antígenos de quistes y trofozoítos de 52,62 , 78,110 y $145 \mathrm{kDa}$ fueron reconocidos, al menos, por una de las tres inmunoglobulinas (IgG total, $\lg _{1} \circ \lg _{3}$ ) con frecuencias de 81,9\%; 77,8\%; $94,4 \%$ y $70,8 \%$; $93,1 \%$, y $98,6 \%$, respectivamente. Este hallazgo es importante y permite proponer la posibilidad de utilizarlos en conjunto para el desarrollo de inmunoensayos que detecten anticuerpos $\lg G$ anti-G. duodenalis en suero.

Se sugiere que antes de concretar esta posibilidad, y dada su importancia epidemiológica, sería relevante estudiar el período durante el cual los anticuerpos $\lg G$ total, $\lg _{1}$ e $\lg _{3}$ permanecen en el hospedero después de la resolución de la infección.

\section{Agradecimientos}

Financiado por el Instituto Nacional de SaludColciencias bajo el proyecto de investigación con código 2104-04-10151 del 2000. 


\section{Referencias}

1. Adam RD. Biology of Giardia lamblia. Clin Microbiol Rev 2001;14:447-75.

2. Guimarães S, Sogayar MIL, Franco M. Giardia duodenalis: inter-strain variability of proteins, antigens, proteases, isoenzymes and nucleic acids. Rev Inst Med Trop S Paulo 1999;41:45-58.

3. Eckmann L, Gillin FD. Microbes and microbial toxins: paradigms for microbial-mucosal interactions I. Pathophysiological aspects of enteric infections with the lumen-dwelling protozoan pathogen Giardia lamblia. Am J Physiol Gastrointest Liver Physiol 2001;280:G1-G6.

4. Haralabidis ST. Inmunodiagnosis of giardiasis by ELISA and studies on cross-reactivity between the anti-Giardia lamblia antibodies and some heterologous parasitic antigens and fractions. Ann Trop Med Parasitol 1984;78: 295-300.

5. Goka AKJ, Rolston DDK, Mathan VI, Farthing MJG. Diagnosis of giardiasis by specific IgM antibody enzymelinked immunosorbent assay. Lancet 1986;ii:184-6.

6. O’Shea-Alvarez MS, González-Robles A, Chavez B, Cedillo-Rivera R. Ultrastructural localization of Giardia lamblia antigens by human IgA and IgG. Arch Med Res 1994;25:407-12.

7. Smith PD, Gillin FD, Brown WR, Nash TE. IgG antibody to Giardia lamblia detected by enzyme-linked immunosorbent assay. Gastroenterology 1981;80:147680 .

8. Smith PD, Gillin FD, Kaushal NA, Nash TE. Antigenic analysis of Giardia lamblia from Afghanistan, Puerto Rico, Ecuador, and Oregon. Infect Immun 1982;36:714-9.

9. Nash TE, Aggarwal A, Adam DR, Conrad JT, Merritt JW. Antigenic variation in Giardia lamblia. J Immunol 1988;141:636-41.

10. Aggarwal A, Nash TE. Antigenic variation of Giardia lamblia in vivo. Infect Immun 1988;56:1420-3.

11. Faubert GM. Immune response to Giardia duodenalis. Clin Microbiol Rev 2000;13:35-54.

12. Rosales-Borjas DM, Díaz-Rivadeneira J, Doña-Leyva A, Zambrano-Villa SA, Mascaró C, Osuna A, et al. Secretory immune response to membrane antigens during Giardia lamblia infection in humans. Infect Immun 1998;66:756-9.

13. Hill DR. Giardiasis. Issues in diagnosis and management. Infect Dis Clin North Am 1993;7:503-25.

14. Ouchterlony 0 . Diffusion in gel methods for immunological analysis. Proc Allergy 1958;5:1.

15. Duque S, Nicholls RS, Arévalo A, Guerrero R. Serodiagnóstico de giardiosis: identificación de inmunoglobulina $\mathrm{G}$ anti-Giardia duodenalis en suero mediante ELISA. Biomédica 2001;21:228-33.
16. Bradford MM. A rapid and sensitive method for the quantitation of microgram quantities of protein utilizing the principle of protein-dye binding. Anal Biochem 1976;72:248-54.

17. Laemmli UK. Cleavage of structural proteins during the assembly of the head of bacteriophage T4. Nature 1970; 227:680-5.

18. Towbin H, Staehelin T, Gordon J. Electrophoretic transfer of proteins from polyacrilamide gels to nitrocellulose sheets: procedures and some applications. Proc Natl Acad Sci USA 1979;76:4350-4.

19. Young JD, Young TM, Lu LP, Unkeless JC, Cohn ZA. Characterization of a membrane pore-forming protein from Entamoeba histolytica. J Exp Med 1982;156: 1667-90.

20. Wolfe MS. Giardiasis. Clin Microbiol Rev 1992;5:93 100.

21. Manson-Bahr PEC, Bell DR. Manson's Tropical diseases. $19^{\text {th }}$ ed. London: Bailliére Tindall; 1987.

22. Janoff EN, Smith PD, Blaser MJ. Acute antibody responses to Giardia lamblia are depressed in patients with AIDS. J Infect Dis 1988;157:798-804.

23. Soliman MM, Taghi-Kilani R, Ahmed FA, Abou- Shady AFA, El-Mageid SAA, Handousa AA, et al. Comparison of serum antibody responses to Giardia lamblia of symptomatic and asymptomatic patients. Am J Trop Med Hyg 1998;58:232-9.

24. Taylor GD, Wenman WM. Human immune response to Giardia lamblia. J Infect Dis 1987;155:137-40.

25. Venkatesan P, Wakelin D. ELISAs for parasitologist: or lies, damned lies and ELISAs. Parasitol Today 1993; 9:228-32.

26. Renart J, Behrens MM, Fernández-Renart $\mathbf{M}$, Martínez JL. Immunoblotting techniques. En: Diamandis EP, Christopoulos TK, editors. Immunoassay. San Diego: Academic Press; 1996. p.537-54.

27. Erlandsen SL, Bemrick WJ, Schupp DE, Shields JM, Jarroll EL, Sauch JF, et al. High-resolution immunogold localization of Giardia cyst wall antigens using field emission SEM with secondary and backscatter electron imaging. J Histochem Cytochem 1990;38:625-32.

28. Crossley R, Holberton DV. Characterization of proteins from the cytoskeleton of Giardia lamblia. J Cell Sci 1985; 59:81-103.

29. Gillin FD, Reiner DS, Gault MJ, Douglas H, Das S, Wunderlich A, et al. Encystation and expression of cyst antigens by Giardia lamblia in vitro. Science 1987; 235:1040-3.

30. Faubert GM, Belosevic M. Animal models for Giardia duodenalis type organisms. En: Meyer EA, editor. Human parasitic diseases. Amsterdam: Elsevier Science Publishers Biomedical Division; 1990. p.77-90. 
31. Bienz M, Wittwer P, Zimmermann V, Müller N. Molecular characterization of a predominant antigenic region of Giardia lamblia variant surface protein $\mathrm{H} 7$. Int J Parasitol 2001;31:827-32.

32. Guimarães S, Sogayar MIL, Franco M. Analysis of proteins from membrane and soluble fractions of Giardia duodenalis trophozoites of two Brazilian axenic strains. Rev Inst Med Trop S Paulo 2002;44:239-44.

33. Char S, Shetty N, Narasimba M, Elliot E, Macaden R, Farthing MJG. Serum antibody response in children with Giardia lamblia infection and identification of an immunodominant 57-kilodalton antigen. Parasite Immunol 1991;13:329-37.

34. Reiner DS, Gillin FD. Human secretory and serum antibodies recognize environmentally induced antigens of Giardia lamblia. Infect Immun 1992;60:637-43.

35. Char S, Cevallos AM, Yamson P, Sullivan PB, Neale G, Farthing MJG. Impaired IgA response to Giardia heat shock antigen in children with persistent diarrhoea and giardiasis. Gut 1993;34:38-40.

36. Thompson RCA, Reynoldson JA, Mendis AHW. Giardia and giardiasis. Adv Parasitol 1993;32:71-160.

37. Belosevic M, Faubert GM, Dharampaul S. Antimicrobial action of antibodies against Giardia muris trophozoites. Clin Exp Immunol 1994;95:485-9.

38. Heyworth MR. Relative susceptibility of Giardia muris trophozoites to killing by mouse antibodies of different isotypes. J Parasitol 1992;78:73-6.
39. Stevens R, Dichek D, Keld B, Heiner D. $\lg _{\text {, }}$ is the predominant subclass of in vivo and in vitro-produced anti-tetanus toxoid antibodies and also serves as the membrane IgG molecule for delivering inhibitory signals to anti-tetanus toxoid antibody-producing cells. J Clin Immunol 1983;3:65-9.

40. Perlmutter RP, Hansburg D, Briles DE, Nicilotti RA, Davie JM. Subclass restriction of murine anticarbohydrate antibodies. J Immunol 1978;121:566-72.

41. Roitt IM. Essential immunology. $8^{\text {th }} \mathrm{ed}$. London: Blackwell Scientific Publications; 1994.

42. Clark JT, Holberton DV. Plasma membrane isolated from Giardia lamblia: identification of membrane proteins. Eur Cell Biol 1986;42:200-6.

43. Einfeld DA, Stibbs HH. Identification and characterization of a major surface antigen of Giardia lamblia. Infect Immun 1984;46:377-83.

44. Das S, Traynor-Kaplan A, Reiner DS, Meng TC, Gillin FD. A surface antigen of Giardia lamblia with a glycosylphosphatidylinositol anchor. J Biol Chem 1991; 266:21318-23.

45. Torian BE, Barnes RC, Stephens RS, Stibbs HH. Tubulin and high-molecular-weight polypeptides as Giardia lamblia antigens. Infect Immun 1984;46:152-8.

46. Rosoff JD, Stibbs HH. Physical and chemical characterization of Giardia lamblia-specific antigen useful in the coprodiagnosis of giardiasis. J Clin Microbiol 1986; 24:1079-83. 